\title{
Are There Bubbles in the Sterling-dollar \\ Exchange Rate? \\ New Evidence from Sequential ADF Tests
}

$\underline{v}$

Timo Bettendorf* Wenjuan Chen**

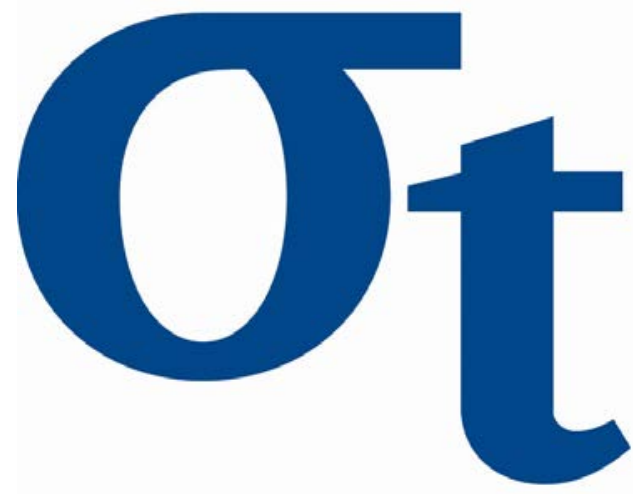

* University of Kent, United Kingdom

** Freie Universität Berlin, Germany

This research was supported by the Deutsche Forschungsgemeinschaft through the SFB 649 "Economic Risk".

http://sfb649. wiwi.hu-berlin.de ISSN 1860-5664 


\title{
Are There Bubbles in the Sterling-dollar Exchange Rate? New Evidence from Sequential ADF Tests
}

\author{
Timo Bettendorf* \\ University of Kent
}

\author{
Wenjuan Chen ${ }^{\dagger}$ \\ Freie Universität Berlin
}

February 20, 2013

\begin{abstract}
There has been mixed evidence regarding the existence of rational bubbles in the foreign exchange markets. This paper introduces recently developed sequential unit root tests into the analysis of exchange rates bubbles. We find strong evidence of explosive behavior in the nominal Sterling-dollar exchange rate. However, this explosive behavior should not be simply interpreted as evidence of rational bubbles, as we show that it might be driven by the relative prices of traded goods.
\end{abstract}

Keywords: exchange rates, rational bubbles, sequential unit root test JEL classifications: C1, F3

\footnotetext{
*University of Kent, School of Economics, Keynes College, United Kingdom, CT27 NP, E-Mail: tb279@kent.ac.uk, Tel.: +44-(0)1227-824-6132, corresponding author.

${ }^{\dagger}$ Freie Universität Berlin, Institut für Statistik und Ökonometrie, Boltzmannstrasse 20, 14195 Berlin, Germany, E-Mail: wenjuan.chen@fu-berlin.de, Tel.: +49-(0)30-838-53240.
} 


\section{Introduction}

Following the breakdown of the Bretton-Woods system of fixed exchange rates in the early 1970s, major developed countries switched from fixed into a floating exchange rate regime. On the foreign exchange spot market, the British pound US dollar is one of the most heavily traded bilateral currency pairs. History has witnessed many episodes of crises in the Sterling-dollar exchange market, such as the 1976 Sterling crisis, the 1992 Black Wednesday UK currency crisis, and the recent 2008 financial crisis. Dramatic depreciation of the Sterling-dollar rate during these crisis periods has puzzled practitioners as well as researchers. Some economists conjecture that speculative bubbles are driving the market during these periods. For example, Evans (1986) finds significant evidence of bubbles in the Sterlingdollar exchange rate in the early 1980s, while Meese (1986), West (1987) and Wu (1995) yield mixed results.

Recently, various new tests have been developed to detect speculative bubbles in asset prices, including Al-Anaswah and Wilfling (2011), Lammerding et al. (forthcoming), Phillips et al. (2011b) and Phillips et al. (2011a). The sequential unit root tests proposed by Phillips et al. (2011b) and Phillips et al. (2011a) are based on the type of indirect stationarity tests initiated by Diba and Grossman (1984) and Hamilton and Whiteman (1985). These indirect tests have the advantage of detecting speculative bubbles despite a potential misspecification of the market fundamental process.

This paper is the first that applies the sequential unit root tests so as to shed new light on the debate on the existence of rational bubbles in exchange rates ${ }^{1}$. We find strong evidence for explosive behavior in the nominal Sterling-dollar exchange rates. In order to shed light on the causes of the explosiveness, we also test for explosive behavior in the underlying fundamentals. Engel (1999) points out that movements in the US exchange rate are mainly driven by the relative prices of traded goods. Therefore we follow Engel (1999) and construct two types of fundamentals for exchange rates, the relative prices of traded and nontraded goods. Results show that the traded goods fundamental may explain the explosiveness in the Sterling-dollar exchange rate. Our results thus shed doubt on claims that the Sterling-dollar exchange has been driven by speculative bubbles.

The remainder of the article is organized as follows: Section 2 describes the rational bubble model of the foreign exchange rate. Section 3 briefly introduces the econometric methods that we have applied. Section 4 presents the evidence on the explosiveness of the Sterling-dollar exchange rate and Section 5 concludes.

\section{Rational Bubbles in Exchange Rate Dynamics}

As stated by Obstfeld and Rogoff (1996, p. 529), "the nominal exchange rate must be viewed as an asset price", which implies that it is determined by current and expected values of

\footnotetext{
${ }^{1}$ Another interesting application of the sequential unit root tests is the recent study by Pavlidis et al. (2012) who test the Efficient Market Hypothesis with forward exchange rates. The tests have also been applied to study existence of speculative bubbles in commodity price and housing prices by Gutierrez (forthcoming), Phillips and $\mathrm{Yu}$ (2011) and Bohl et al. (forthcoming).
} 
fundamentals. We thus assume the following present value model of exchange rate in line with Engel and West (2005) and Leon-Ledesma and Mihailov (forthcoming):

$$
s_{t}=(1-\gamma) \sum_{j=0}^{k} \gamma^{j} E_{t}\left[f_{t+j}\right]+\gamma^{k+1} E_{t}\left[s_{t+k+1}\right],
$$

where $s_{t}$ is the nominal exchange rate at time $t$, and $f_{t}$ is the market fundamental at time period $t$. $\gamma$ denotes the discount factor. By imposing the transversality condition

$$
\lim _{k \rightarrow \infty} \gamma^{k} E_{t}\left[s_{t+1}\right]=0,
$$

we assure that the exchange rate will only depend on future expected fundamentals in the long run. However, if the transversality condition does not hold, the exchange rate may be subject to an explosive rational bubble. Assuming that the bubble follows an AR(1) process, it can be written as

$$
b_{t}=\frac{1}{\gamma} b_{t-1}+\varepsilon_{t}
$$

where the first-order autoregressive coefficient $\frac{1}{\gamma}$ is greater than 1 , as the bubble is an explosive process. Errors are captured by $\varepsilon_{t} \sim N I D\left(0, \sigma^{2}\right)$. Therefore, we can write the exchange rate as

$$
s_{t}=s_{t}^{f}+b_{t} \quad \text { or } \quad s_{t}-s_{t}^{f}=b_{t},
$$

where $s_{t}^{f}$ denotes the fundamental component of the exchange rate and $b_{t}$ represents the bubble component. We employ the purchasing power parity (PPP) fundamental

$$
s_{t}^{f}=p_{t}-p_{t}^{*},
$$

where $p_{t}$ denotes the log level of the domestic price index. Asterisks are used for foreign counterparts. For decomposing the price index into indexes of nontraded and traded goods, Engel (1999) considers a price index for a country as a weighted average of traded- and nontraded- goods prices $p_{t}=(1-\alpha) p_{t}^{T}+\alpha p_{t}^{N} \cdot p_{t}^{T}$ stands for the log of the traded goods price index, and $p_{t}^{N}$ stands for the log of the nontraded goods price index. For the foreign country, one can also write $p_{t}^{*}=(1-\beta) p_{t}^{T *}+\beta p_{t}^{N *}$. Thus it follows:

$$
p_{t}-p_{t}^{*}=p_{t}^{T}-p_{t}^{T *}+\alpha\left(p_{t}^{N}-p_{t}^{T}\right)-\beta\left(p_{t}^{N *}-p_{t}^{T *}\right)
$$

Equation (5) shows that the relative price differential can be decomposed into two components, the traded goods component, and the nontraded goods component which is a weighted difference of the relative prices of nontraded-to traded-goods prices in each country $s_{t}^{f, N}$ :

$$
s_{t}^{f}=s_{t}^{f, T}+s_{t}^{f, N}
$$

The produce price index (PPI) is the most broadly available and frequently used index to represent the price level of traded goods. Though there are some producer goods that are not traded, PPI is measured at the production site and thus exclude marketing and other 
nontraded consumer services. Thus we construct the traded goods component using the PPI following Engel (1999):

$$
s_{t}^{f, T}=\ln \left(P P I_{t}\right)-\ln \left(P P I_{t}^{*}\right),
$$

The relative nontraded goods component is constructed from the aggregate consumer price indexes (CPI) relative to aggregate PPI:

$$
s_{t}^{f, N}=\ln \left(C P I_{t}\right)-\ln \left(P P I_{t}\right)-\left(\ln \left(C P I_{t}^{*}\right)-\ln \left(P P I_{t}^{*}\right)\right) .
$$

In the following section, we demonstrate how explosiveness can be detected in the nominal Sterling-dollar exchange rates $s_{t}$, the real exchange rate of nontraded goods $s_{t}-s_{t}^{f, N}$, and the real exchange rate of traded goods $s_{t}-s_{t}^{f, T}$ using recursive right-tailed unit root tests by Phillips et al. (2011b) and Phillips et al. (2011a).

\section{The Sequential ADF Tests}

Phillips et al. (2011b) provide a new framework to test for bubble phenomena in asset prices. Homm and Breitung (2012) show that this sup ADF (SADF) test is capable of detecting periodically collapsing bubbles and is robust against multiple breaks due to a possible burst of the bubble. The test procedure is based on the autoregressive process

$$
x_{t}=\mu+\delta x_{t-1}+\sum_{j=1}^{J} \phi_{j} \Delta x_{t-j}+\varepsilon_{t},
$$

where $x_{t}$ is the time series of interest, $E\left(\varepsilon_{t}\right)=0$ and $E\left(\varepsilon_{t}^{2}\right)=\sigma^{2}$. The unit root null hypothesis is $H_{0}: \delta=1$ and the right-tailed alternative hypothesis is $H_{1}: \delta>1$.

Given a fraction $r_{0}$ of the total sample as an initial window size, Equation (9) is estimated recursively fixing the first observation as the starting the point, and using the subsets of sample data increased by one observation stepwise.

For a subsample starting from the first observation and at a fractional size of the full sample $r_{2}$, where $r_{0}<r_{2} \leq 1$, the corresponding ADF test statistic can be denoted by $A D F_{r_{2}}$. Hence $A D F_{1}$ corresponds to the ADF test statistic of the full sample. The SADF test statistic is thus the supremum value of $A D F_{r_{2}}$, for $r_{0}<r_{2} \leq 1$.

$$
\operatorname{SADF}\left(r_{0}\right)=\sup _{r_{2} \in\left[r_{0}, 1\right]}\left\{A D F_{r_{2}}\right\}
$$

Evidence of explosive behavior is obtained on certain time series if the SADF statistic is larger than the right-side critical values for a chosen nominal size.

One limitation of the SADF test is that the starting point is fixed as the first observation of the sample. This implies that in the presence of two bubbles, the second bubble may not be detected if it is dominated by the first bubble. Therefore, Phillips et al. (2011b) also apply a rolling version of the SADF test, where the starting window is allowed to move over the 
sample. However, the size of the starting window is still fixed, which limits the power of the test. Phillips et al. (2011a) extend the SADF test by nesting it in a loop, which increments the starting point $\left(r_{1} \in\left[0, r_{2}-r_{0}\right]\right)$ each run. The generalized SADF test (GSADF) is able to detect potentially multiple bubbles in the data and thus overcomes the weakness of the SADF test:

$$
\operatorname{GSADF}\left(r_{0}\right)=\sup _{r_{2} \in\left[r_{0}, 1\right], r_{1} \in\left[0, r_{2}-r_{0}\right]}\left\{A D F_{r_{1}}^{r_{2}}\right\} .
$$

Consequently, both the SADF test and the rolling SADF test are nested in the GSADF test. It is important to note that the tests may fail to detect an early bubble if the starting window size is too large.

\section{Explosive Behavior in the Sterling-dollar Exchange Rates}

Our study focuses on the bilateral exchange rates between the United States and the Great Britain. We obtained time series of the British Pound/ US dollar exchange rate from the OECD database. The time series of the consumer price index (US) and retailer price index (UK) as well as the producer price index (PPI) are obtain from the IMF International Financial Statistics and used for constructing the fundamentals of the exchange rates. All times series are transformed into logarithm. We work with monthly data, because a higher frequency of price data is not available. The data sample ranges from 1972 M1 to 2012 M6 and covers 486 monthly observations. Hence, our sample covers the period after the breakdown of the Bretton-Woods system of fixed exchange rates. We set the lag order to zero for all time series, because Phillips et al. (2011a) demonstrate with Monte-Carlo simulations that lag selection criteria such as Campbell and Perron (1991) result in significant size distortion and lower power of both the SADF and the GSADF tests.

Results for the nominal Sterling-dollar exchange rate $s_{t}$ are shown at the third row of Table 1. The standard right-sided ADF test statistic seems to suggest no explosive behavior in the nominal exchange rate. However, this result could be misleading if periodically collapsing bubbles occur during the given period (see Evans (1991)). The SADF and the GSADF tests are capable of overcoming this shortcoming. The null hypothesis that there is no explosive behavior in the nominal Sterling-dollar exchange rate is rejected at the $1 \%$ significance level for the SADF test. Non-explosiveness is also rejected at the $5 \%$ significance level according to the GSADF test. Figure 1 shows the time series of the log nominal exchange rate and the corresponding sequence of $A D F_{t}$ statistics. The $A D F_{t}$ sequence displays clear evidence of multiple periods of explosiveness. First, the test reports explosiveness in 1976, which corresponds to the 1976 Sterling crisis. Secondly, we find explosiveness in 1985. At that time, the US dollar appreciated heavily against several currencies.

The explosiveness in the nominal exchange rate could be driven either by rational bubbles or explosive fundamentals. The fourth row of Table 1 shows the test results for the real exchange rate of nontraded goods $s_{t}-s_{t}^{f, N}$. The exchange rate remains explosive after the relative prices of nontraded goods are accounted for. Figure 2(a) displays the sequence of the $A D F_{t}$ statistics for the real exchange rate of nontraded goods, which behaves very similar 
Table 1: Tests for Explosive Behavior in the Sterling-dollar Exchange Rate

\begin{tabular}{l|l|l|l}
\hline \hline & \multicolumn{3}{|c}{ Sample: 1972 M1-2012 M6 } \\
\hline Variable & ADF & SADF & GSADF \\
\hline$s_{t}$ & -2.478 & $2.128^{* *}$ & $2.416^{*}$ \\
$s_{t}-s_{t}^{f, N}$ & -1.934 & $2.630^{* *}$ & $2.794^{*}$ \\
$s_{t}-s_{t}^{f, T}$ & -1.827 & 0.374 & 1.623 \\
\hline CV 1\% & 0.614 & 1.984 & 2.860 \\
CV 5\% & -0.091 & 1.490 & 2.340 \\
CV 10\% & -0.451 & 1.218 & 2.106 \\
\hline
\end{tabular}

This table shows the various test statistics of the nominal exchange rates $s_{t}$, the real exchange rates of nontraded goods $s_{t}-s_{t}^{f, N}$, and the real exchange rates of traded goods $s_{t}-s_{t}^{f, T}$ (see Equation (7) and Equation (8)). The initial window size $r_{0}$ is set as three years (36 observations) for the SADF and GSADF tests. Critical Values are obtained from Monte-Carlo simulations with 5000 replications for the ADF, SADF and GSADF tests. The items marked with * are significant at $5 \%$ significance level, and the items market with ** are significant at $1 \%$ significance level.

Figure 1: The Nominal Sterling-dollar Exchange Rate

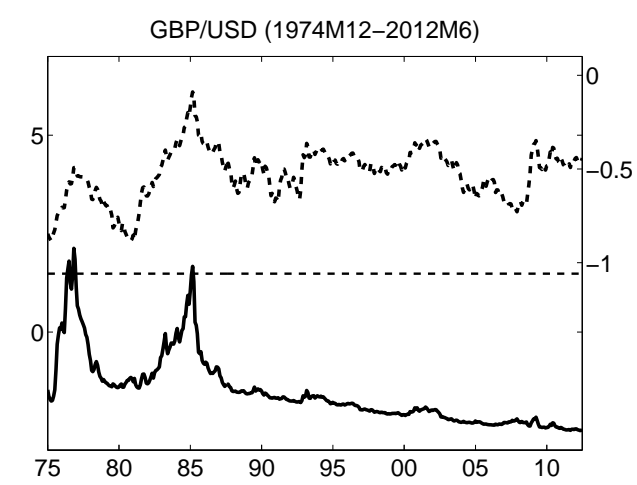

Note: This graph shows the series of the nominal Sterling dollar exchange rate $s_{t}$ (right, dotted) and its corresponding sequence of ADF statistics (left, solid). The dashed line represents the $5 \%$ critical values of the SADF test.

to those of the nominal exchange rate $s_{t}$ in Figure 1 . Thus the relative prices of nontraded goods $s_{t}^{f, N}$ play no role in explaining the explosiveness in the nominal exchange rate.

In contrast, no evidence of explosive behavior is found in the real exchange rates of traded goods $s_{t}-s_{t}^{f, T}$. The null hypothesis that the series is nonexplosive can not be rejected at the $10 \%$ significance level for either the SADF or the GSADF test. Figure 2(b) displays the result of the SADF test graphically. The GSADF statistics show exactly the same pattern (see online appendix). Therefore, the explosive behavior in the nominal Sterling-dollar exchange rate may be driven by the relative prices of traded goods between the US and the Great 
Britain. $^{2}$ The two periods where the explosiveness diminishes are characterised by large commodity shocks. Moreover, manufacturing and mining, two large sectors in the UK until the mid-1980s, were heavily unionised, creating large wage-price spirals. Both effects may have driven up UK PPI inflation causing the observed pattern.

Figure 2: The Real Sterling-dollar Exchange Rates

(a) The Real Exchange Rate of Non Traded Goods

(b) The Real Exchange Rate of Traded Goods
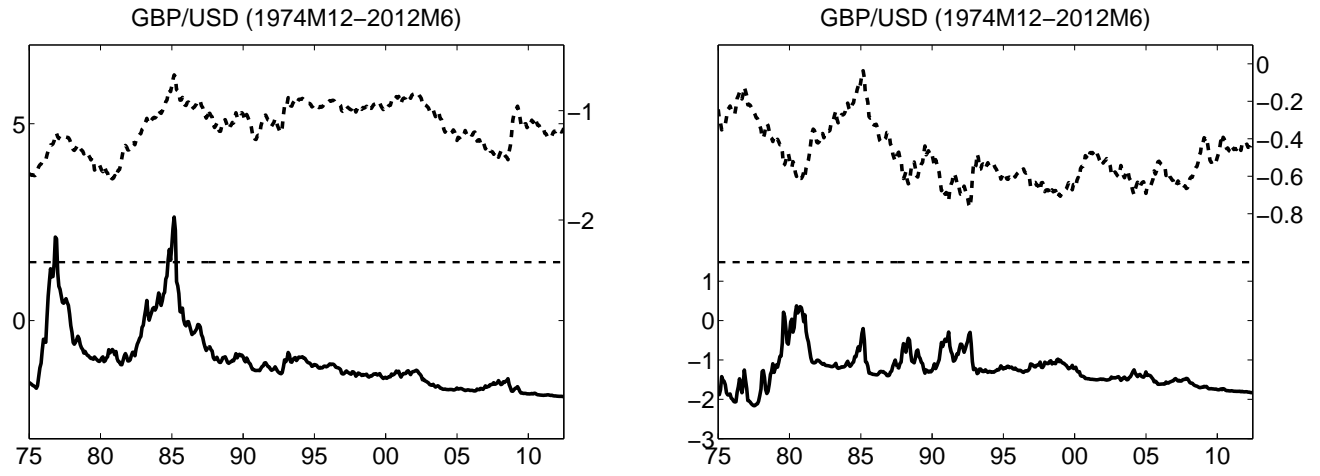

Note: The left panel shows the series of the real exchange rate of nontraded goods $s_{t}-s_{t}^{f, N}$ (right, dotted) and its corresponding sequence of ADF statistics (left, solid). The right panel shows the series of the real exchange rate of traded goods $s_{t}-s_{t}^{f, T}$ (right, dotted) and its corresponding sequence of ADF statistics (left, solid). The dashed line represents the $5 \%$ critical values of the SADF test.

These findings are not in favor of the speculative bubble hypothesis in the nominal Sterling-dollar exchange rate, because the explosive behavior in the exchange rate may be driven by the relative prices of trades goods. Our results are in accordance with those of Engel (1999) and Betts and Kehoe (2005) who show that the relative prices of traded goods explain most of the movements in exchange rates.

\section{Conclusion}

In this paper we provide new evidence casting doubt on the bubble hypothesis in the nominal Sterling-dollar exchange rates by employing recent sequential ADF tests developed by Phillips et al. (2011b) and Phillips et al. (2011a). Though we find explosive behavior in the nominal exchange rates, the explosiveness coincides with explosive behavior in the relative prices of traded goods. In line with Engel (1999) and Betts and Kehoe (2005), our results indicate that the relative prices of nontraded goods play little role in the movements of exchange rates, while the relative prices of traded goods seem to be an important determinant

\footnotetext{
${ }^{2}$ As a robustness check, we test the price ratios separately. The series $s_{t}^{f, T}$ exhibits explosiveness during the two periods where the explosiveness in the real exchange rate of traded goods diminishes. Results are available on request.
} 
behind the movements of exchange rates. Our results demonstrate that it is crucial to take fundamentals into account when identifying rational bubbles in asset prices, because explosiveness in the asset price alone is not a sufficient condition. This is an important insight for policy makers and practitioners as well.

\section{Acknowledgements}

We thank Dieter Nautz, Miguel León-Ledesma, two anonymous referees as well as participants of the Research Seminar at the University of Kent and participants of the Empirical Macroeconomics Workshop at Free University of Berlin for their valuable comments. Funding by the Deutsche Forschungsgemeinschaft through the CRC 649 'Economic Risk' is greatly acknowledged. We also thank the members of the Research Center of Deutsche Bundesbank for their support during the research visit of both authors.

\section{References}

Al-Anaswah, N. and Wilfling, B. (2011). Identification of speculative bubbles using state-space models with markov-switching. Journal of Banking $\&$ Finance, 35 (5), 10731086.

Betts, C. M. and Kenoe, T. J. (2005). Real exchange rate movements and the relative price of non-traded goods. NBER Working Paper No. $1443 \%$.

Bohl, M., Kaufmann, P. and Stephan, P. (forthcoming). From hero to zero: Evidence of performance reversal and speculative bubbles in german renewable energy stocks. Energy Economics.

Campbell, J. and Perron, P. (1991). Pitfalls and opportunities: what macroeconomists should know about unit roots. NBER Working Paper No. 100.

Diba, B. and Grossman, H. (1984). Rational bubbles in the price of gold. NBER Working Paper No. 1300.

Engel, C. (1999). Accounting for U.S. Real Exchange Rate Changes. Journal of Political Economy, 107 (3), 507-538.

- and West, K. D. (2005). Exchange rates and fundamentals. Journal of Political Economy, 113 (3), 485-517.

Evans, G. W. (1986). A test for speculative bubbles in the sterling-dollar exchange rate: 1981-84. American Economic Review, 76 (4), 621-636.

- (1991). Pitfalls in testing for explosive bubbles in asset prices. American Economic Review, 81 (4), 922-930. 
Gutierrez, L. (forthcoming). Speculative bubbles in agricultural commodity markets. European Review of Agricultural Economics.

Hamilton, J. and Whiteman, C. (1985). The observable implications of self-fulfilling expectations. Journal of Monetary Economics, 16 (3), 353-373.

Homm, U. and Breitung, J. (2012). Testing for speculative bubbles in stock markets: A comparison of alternative methods. Journal of Financial Econometrics, 10 (1), 198-231.

Lammerding, M., Stephan, P., Trede, M. and B., W. (forthcoming). Speculative bubbles in recent oil price dynamics: Evidence from a bayesian markov-switching. Energy Economics.

Leon-Ledesma, M. and Mihailov, A. (forthcoming). Advanced International Macroeconomics and Finance. Oxford University Press.

Meese, R. A. (1986). Testing for bubbles in exchange markets: A case of sparkling rates. Journal of Political Economy, 94 (2), 345-373.

Obstfeld, M. and Rogoff, K. (1996). Foundations of International Macroeconomics. Cambridge: MIT Press.

Pavlidis, E., PAyA, I. and Peel, D. (2012). A new test for rational speculative bubbles using forward exchange rates: The case of the interwar german hyperinflation. Lancaster University Working paper 7/09/2012.

Phillips, P. C. B., Shi, S. and Yu, J. (2011a). Testing for multiple bubbles. Singapore Management University Working Paper No. 09-2011.

-, Wu, Y. and Yu, J. (2011b). Explosive behaviour in the 1990s nasdaq: When did exuberance escalate asset values? International Economics Review, 52 (1), 201-226.

- and YU, J. (2011). Dating the timeline of financial bubbles during the subprime crisis. Quantitative Economics, 2 (3), 455-491.

West, K. D. (1987). A standard monetary model and the variability of the deutschemarkdollar exchange rate. Journal of International Economics, 23 (1-2), 57-76.

Wu, Y. (1995). Are there rational bubbles in foreign exchange markets? evidence from an alternative test. Journal of International Money and Finance, 14 (1), 27-46. 


\section{Online Appendix}

\section{A GSADF test statistics}

Here, we present the results of the GSADF tests graphically. Figure 1 and 2 show that the results obtained from the GSADF test are in line with those obtained from the SADF test.

Figure 1: The Nominal Sterling-dollar Exchange Rate

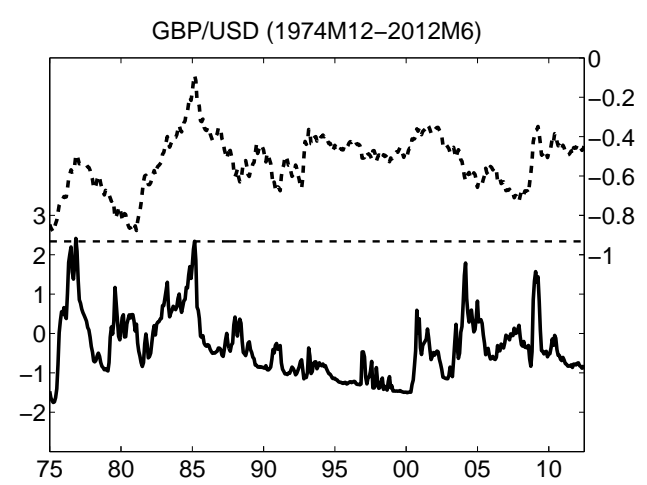

Note: This graph shows the series of the nominal Sterling dollar exchange rate $s_{t}$ (right, dotted) and its corresponding sequence of ADF statistics (left, solid). The dashed line represents the 5\% GSADF critical values.

Figure 2: The Real Sterling-dollar Exchange Rates

(a) The Real Exchange Rate of Non Traded Goods

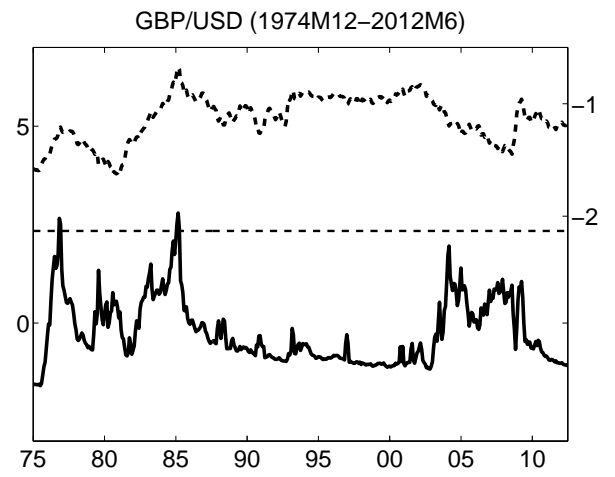

(b) The Real Exchange Rate of Traded Goods

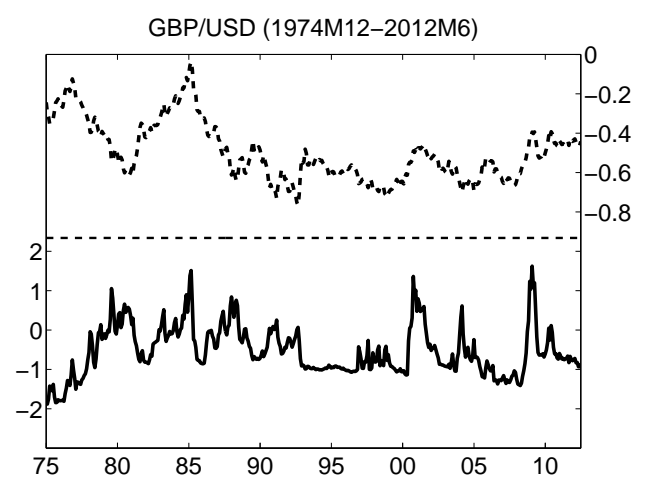

Note: The left panel shows the series of the real exchange rate of non-traded goods $s_{t}-s_{t}^{f, N}$ (right, dotted) and its corresponding sequence of ADF statistics (left, solid). The right panel shows the series of the real exchange rate of traded goods $s_{t}-s_{t}^{f, T}$ and its corresponding sequence of ADF statistics. The dashed line represents the $5 \%$ GSADF critical values. 


\section{SFB 649 Discussion Paper Series 2013}

For a complete list of Discussion Papers published by the SFB 649, please visit http://sfb649. wiwi.hu-berlin. de.

001 "Functional Data Analysis of Generalized Quantile Regressions" by Mengmeng Guo, Lhan Zhou, Jianhua Z. Huang and Wolfgang Karl Härdle, January 2013.

002 "Statistical properties and stability of ratings in a subset of US firms" by Alexander B. Matthies, J anuary 2013.

003 "Empirical Research on Corporate Credit-Ratings: A Literature Review" by Alexander B. Matthies, January 2013.

004 "Preference for Randomization: Empirical and Experimental Evidence" by Nadja Dwenger, Dorothea Kübler and Georg Weizsäcker, January 2013.

005 "Pricing Rainfall Derivatives at the CME" by Brenda López Cabrera, Martin Odening and Matthias Ritter, January 2013.

006 "Inference for Multi-Dimensional High-Frequency Data: Equivalence of Methods, Central Limit Theorems, and an Application to Conditional Independence Testing" by Markus Bibinger and Per A. Mykland, January 2013.

007 "Crossing Network versus Dealer Market: Unique Equilibrium in the Allocation of Order Flow" by Jutta Dönges, Frank Heinemann and Tijmen R. Daniëls, January 2013.

008 "Forecasting systemic impact in financial networks" by Nikolaus Hautsch, Julia Schaumburg and Melanie Schienle, January 2013.

009 "I'll do it by myself as I knew it all along': On the failure of hindsightbiased principals to delegate optimally" by David Danz, Frank Hüber, Dorothea Kübler, Lydia Mechtenberg and J ulia Schmid, J anuary 2013.

010 "Composite Quantile Regression for the Single-Index Model" by Yan Fan, Wolfgang Karl Härdle, Weining Wang and Lixing Zhu, February 2013.

011 "The Real Consequences of Financial Stress" by Stefan Mittnik and Willi Semmler, February 2013.

012 "Are There Bubbles in the Sterling-dollar Exchange Rate? New Evidence from Sequential ADF Tests" by Timo Bettendorf and Wenjuan Chen, February 2013. 